\title{
Giant dentigerous cyst occupying the right hemimandible
}

\author{
Uğur Koçer $M D^{1}$, H Mete Aksoy $M D^{1}$, Yiğit Ö Tiftikçioğlu $M D^{1}$, \\ Dilek Ertoy $\mathrm{MD}^{2}$, Önder Karaaslan MD ${ }^{1}$
}

U Koçer, HM Aksoy, YÖ Tiftikçioğlu, D Ertoy, Ö Karaaslan. Giant dentigerous cyst occupying the right hemimandible. Can J Plast Surg 2002;10(4):171-174.

Dentigerous cysts are the second most common odontogenic cysts of the mandible. They may vary in size from $2 \mathrm{~cm}$ to more than $10 \mathrm{~cm}$. In the present report, a dentigerous cyst with massive involvement of the right half of the mandible in a young patient is presented. For cosmetic reasons and long term risks these cysts must be treated. Surgical removal is the preferred modality and a submandibular route should be chosen in large lesions. Bony cavities may be decreased in volume by using osteoperiosteal flaps, but there is no need for primary bone grafting, even for large defects.

Key Words: Dentigerous cyst; Enucleation; Submandibular route

\section{Kyste dentigère géant occupant l'hémi- mandibule droit}

RÉSUMÉ : Les kystes dentigères viennent au second rang parmi les kystes odontogènes affectant le plus souvent le mandibule. Ils peuvent varier en taille de $2 \mathrm{~cm}$ à plus de $10 \mathrm{~cm}$. Le présent rapport fait état d'un kyste dentigère avec atteinte massive de la moitié droite du mandibule chez un jeune patient. Pour des raisons d'ordre esthétique et à cause des risques à long terme, ces kystes doivent être traités. L'ablation chirurgicale est la modalité à privilégier et la voie sous-mandibulaire est préférable lorsque les lésions sont volumineuses. Les cavités osseuses peuvent être réduites de volume par l'utilisation de lambeaux ostéopériostés, mais il n'est pas nécessaire de recourir à une greffe osseuse primaire, même dans le cas d'anomalies importantes.
$\mathrm{T}$ he dentigerous cyst, also called a follicular or coronodental cyst, is the second most common odontogenic cyst of the mandible $(1,2)$. The dentigerous cyst is also the most common developmental cyst of the jaw and is always associated with an unerupted tooth. The third molar is the tooth that is involved most frequently and the posterior area of the mandible is the most common site of dentigerous cysts $(1,3)$. Those cysts usually present as asymptomatic swellings located in the jaw $(1,2)$. The usual age of diagnosis ranges between 20 and 50 years, although they may be detected in younger patients (2). The size of dentigerous cysts may vary from $2 \mathrm{~cm}$ in diameter to extensive expansion of the involved part of the mandible (1). A huge dentigerous cyst almost completely occupying the right hemimandible in a young patient is presented.

\section{CASE PRESENTATION}

A 16-year-old girl presented with a swelling of five months' duration, located on the right side of her jaw. She declared that the swelling increased gradually in size. There was no accompanying pain. On physical examination, there was a hard, immobile, nontender mass located on the right half of

\footnotetext{
${ }^{1}$ Plastic and Reconstructive Surgery Clinic, Ankara Training and Research Hospital; ${ }^{2}$ Department of Pathology, Hacettepe University School of Medicine, Ankara, Turkey

Correspondence and reprints: Dr Uğur Koçer, Meşrutiyet Cad, Number 17/12, Kizılay, Ankara, 06640, Turkey.

Telephone+90-312-417-55-35, fax+90-312-425-56-33, e-mail u.kocer@yahoo.com
} 


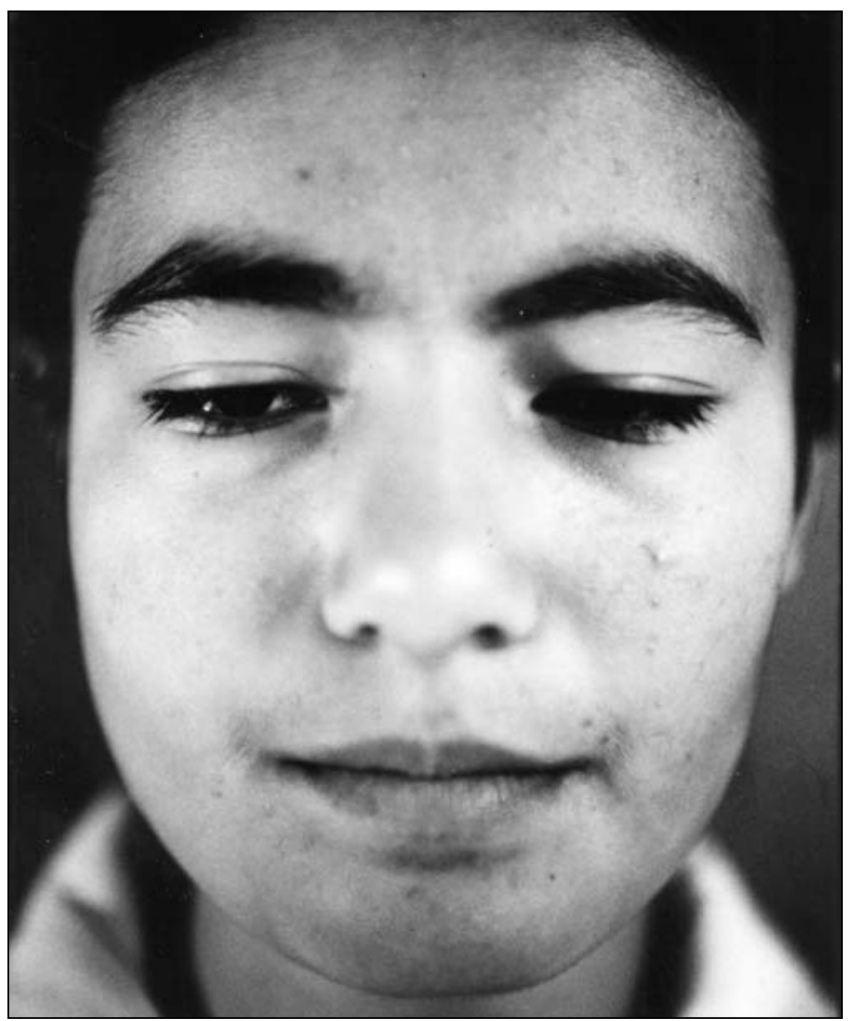

Figure 1) Front view of the patient showing facial asymmetry caused by the cyst

the mandible anterior to the angulus. It caused an asymmetrical appearance of the face (Figure 1). There was no loss of sensation on the lower lip. The mass could also be palpated intraorally. Radiographs of the mandible showed a radiolucent mass containing a partially developed third molar tooth inside, suggesting a dentigerous cyst. The cyst was very large, $11 \mathrm{~cm}$ in its largest diameter. It occupied the ramus and body of the right mandible (Figure 2). The cortex of the mandible was thinned by the expanding cyst. The wall of the cyst was smooth, which was in accordance with slow expansion. Surgery was planned for enucleation of the cyst.

A $3 \mathrm{~cm}$ long incision was made parallel and $2.5 \mathrm{~cm}$ inferior to the lower edge of the mandible. Extreme care was taken to avoid injury to the marginal mandibular branch of the facial nerve. After dissection of the muscular layer, periosteum overlying the cortex of the mandible was reached. Upon stripping off the periosteum, the cortex of the mandible was exposed and was found to be thinned by the expanding lesion. The wall of the cyst was reached and exposed through a bony window created by removing a piece of thinned cortex of the mandible. The cyst was removed by using a blunt dissector and a curette to prevent recurrence. The wall of the cyst contained a partially formed molar tooth (Figure 3). The thinned external cortex of the mandible was collapsed into the bony cavity that remained after enucleation of the cyst in the form of an osteoperiosteal flap to decrease the volume of the cavity.
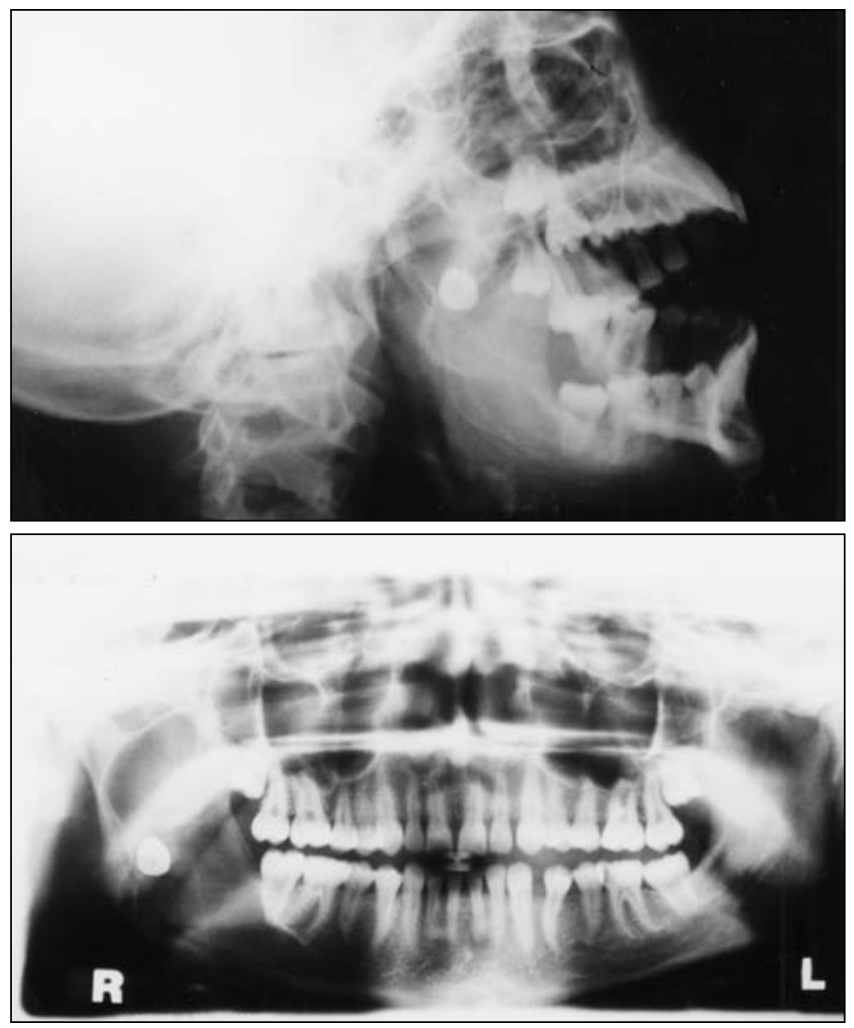

Figure 2) Top Lateral mandibular x-ray showing a unilocular cystic lesion on the right side of the mandible that included a molar tooth. Bottom Panoramic x-ray of the same lesion

A postoperative panoramic $\mathrm{x}$-ray of the mandible was obtained for control. It showed the extent of the bony cavity that was left behind after removal of the cyst (Figure 4). Curetted material was sent to pathology for microscopical examination.

Light microscopy showed a stratified, squamous, epithelial cyst lining without keratinization. Neoplastic transformation was not detected. Subepithelial stroma consisted of mature collagenous tissue. No inflammatory infiltrate was present. The findings were compatible with a dentigerous cyst (Figure 5).

The postoperative period was uneventful except for a short period of marginal mandibular nerve dysfunction, which disappeared completely within a few weeks.

\section{DISCUSSION}

Dentigerous cysts are the developmental odontogenic cysts of the jaw. They arise from the pooling of inflammatory exudate, which is derived from the obstructed follicular veins of an unerupted tooth and accumulates between the reduced enamel epithelium and the crown of the tooth (1). The cyst enlarges by unicentric expansion from the hydrostatic pressure of its contents (1). They are lined by a thin, nonkeratinizing, stratified, squamous epithelium (2).

The posterior area of the mandible is the most common site of dentigerous cysts and the third molar is the tooth that is involved most frequently $(1,3)$. Involvement of the third molar tooth was present in our case. However, 


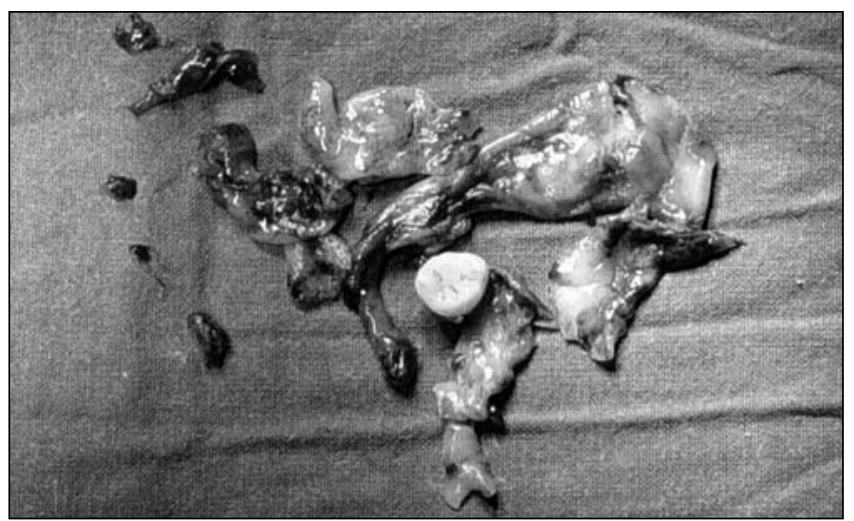

Figure 3) Appearance of the removed specimen containing a partially formed third molar tooth

dentigerous cysts are known to occur anywhere in the mandible, and teeth other than third molar can be associated with the cyst $(4,5)$. There may be more than one cyst in the mandible, and bilateral involvement may be seen (6). About $60 \%$ of dentigerous cysts occur in the mandible, and the rest are encountered in the maxilla, especially in the canine region (2). These cysts range in size from $2 \mathrm{~cm}$ to $10 \mathrm{~cm}$ in diameter (2). In our case, the largest dimension of the cyst was $10 \mathrm{~cm}$ and both posterior and anterior parts of the right hemimandible were occupied by the cyst, which made the case interesting. The largest cysts may cause expansion of bone cortices, and this was observed in our case $(7,8)$. They can also cause displacement of adjacent teeth, sometimes with teeth root resorption (2).

Dentigerous cysts are usually asymptomatic swellings $(1,2)$. They may cause asymmetry of the face and cosmetic problems. This is very important in young patients such as the one in our case. Dentigerous cysts are not associated with pain in the absence of infection (1). Rarely, however, do they expand so rapidly that discomfort will result from pressure on a sensory nerve (1). Sensory nerve dysfunction was not present in our case despite massive involvement of the right half of the mandible.

Differential diagnosis of a dentigerous cyst includes hyperplasic follicular tissue, because both are associated with the crown of an impacted tooth (9). However, other diagnostic possibilities, such as ameloblastoma, should be considered when evaluating a pericoronal cystic lesion. Histopathological examination of all pericoronal cystic lesions should be performed after removal (10). Although radicular cysts have different clinical and radiographical characteristics, those of primary teeth may mimic dentigerous cysts and can be differentiated from them only by pathological examination (11). Both are lined by stratified, squamous epithelium. Radicular cysts may show focal keratinization. Their walls are diffusely infiltrated by persistent inflammatory cells. The absence of microscopical inflammation definitely excluded the diagnosis of radicular cyst in our case.

Dentigerous cysts are associated with a risk of pathological fracture when they reach massive dimensions, as in our

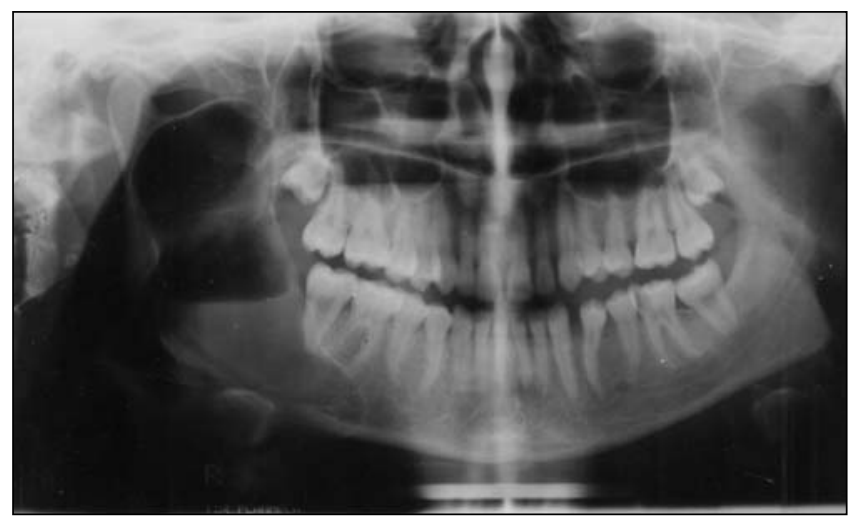

Figure 4) Postoperative control $x$-ray showing the extent of mandibular destruction by the cyst that left behind a cavity extending from the ramus to the second premolar tooth

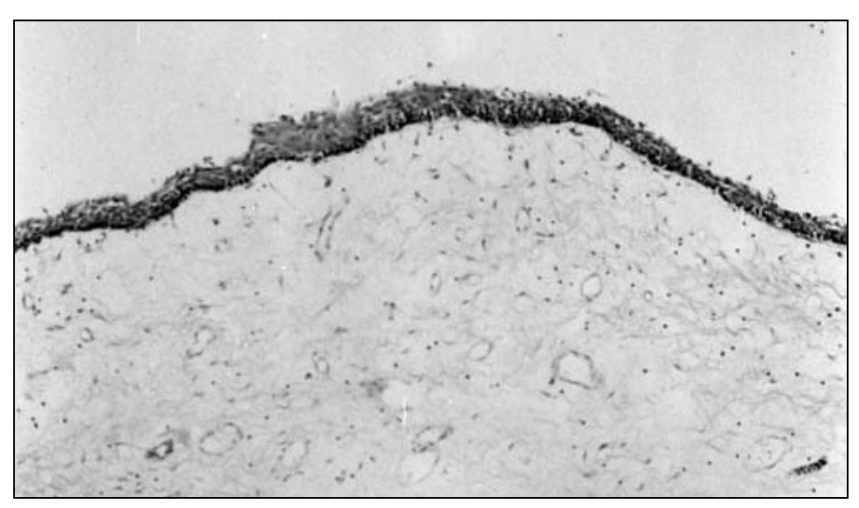

Figure 5) Thin stratified squamous epithelium lining the cyst. No inflammation was noted (hematoxylin and eosin stain, original magnification $\times 40$ )

case. They give rise to cosmetic problems, especially in young patients. There are also long term risks of leaving a dentigerous cyst untreated. It has been reported that ameloblastomas and odontogenic or squamous cell carcinomas may develop in dentigerous cysts (12-14). Therefore, they must be treated considering all the consequences and complications associated with them. Different treatment alternatives are available, such as marsupialization, but enucleation of the cyst is the most widely accepted method of treatment $(2,15)$. For smaller cysts, an intraoral approach is preferred and a mucoperiosteal flap is elevated to reach the cyst wall, but for larger cysts, a submandibular approach should be chosen for complete enucleation of the lesion $(2,16)$. All the cyst lining must be removed; otherwise, there may be a recurrence of the lesion (2). Cavities formed in the mandible after enucleation fill with bone spontaneously over six to 24 months $(2,3)$. In most cases, the expanded lower jaw slowly remodels to a more normal contour (2). Collapsing an osteoperiosteal flap to eliminate dead space after cyst enucleation has been found to be successful in the obliteration of bony defects ranging from 3 to $7 \mathrm{~cm}$ in size (17). We applied this technique and found it to be useful in our case to decrease dead space following cyst removal. Primary bone grafting of defects to decrease the 
risk of pathological fracture has been advocated following enucleation of large dentigerous cysts (2). Severe destruction of bony jaw contours is also accepted as a relative indication for primary bone grafting (2). However, spontaneous filling of bone cavities in time and donor site morbidity associated with bone grafts should make this technique an infrequently used one in the treatment of dentigerous cysts.

\section{REFERENCES}

1. Georgiade NG, Georgiade GS, Harter TB. Solid and cystic tumors of the jaw. In: Georgiade GS, Georgiade NG, Riefkohl R, Barwick WJ, eds. Textbook of Plastic, Maxillofacial and Reconstructive surgery. Baltimore: Williams \& Wilkins, 1996:489-506.

2. Jackson IT, Shaw K. Tumors of the craniofacial skeleton, including the jaws. In: McCarthy JG, ed. Plastic Surgery. Philadelphia: WB Saunders, 1990:3338-40.

3. Carvalho PI, Kumagai LT, Cacavalle AC. Dentigerous cyst associated with an unerupted mandibular third molar. Dentomaxillofac Radiol 1997;26:137.

4. Browne RM. The pathogenesis of odontogenic cysts: A review. J Oral Pathol 1975;4:31-46.

5. Seddon RP, Fung DE, Barnard KM, Smith PB. Dentigerous cysts involving permanent incisors: Four case reports. Int J Paediatr Dent 1992;2:105-11.

6. Crinzi RA. Bilateral dentigerous cysts of the mandible. Oral Surg Oral Med Oral Pathol 1982;54:367.

7. Meara JG, Brown MT, Caradonna D, Varvares MA. Massive, destructive, dentigerous cyst: A case report. Otolaryngol Head Neck Surg 1996;115:141-4.

8. Pinds D. Massive dentigerous cysts. Bull Tri Cty Dent Soc 1966;15:6-7.

9. Sadeghi EM, Sewall SR, Dohse A, Nivak TS. Odontogenic tumors that mimic a dentigerous cyst. Compend Contin Educ Dent 1995;16:500,502,504.

10. Ikeshima A, Ozawa M, Yamamoto H, Araki M, Sairenji E. Differential diagnosis between cyst and tumor: Dentigerous cyst and ameloblastoma containing teeth. J Nihon Univ Sch Dent 1990:32:19-26.

11. Wood RE, Nortje CJ, Padayachee A, Grotepass F. Radicular cysts of primary teeth mimicking premolar dentigerous cysts: Report of three cases. ASDC J Dent Child 1988;55:288-90.

12. McMillan MD, Smillie AC. Ameloblastoma associated with dentigerous cysts. Oral Surg Oral Med Oral Pathol 1982;51:489-96.

13. Olson JW, Miller RL, Kushner GM, Vest TM. Odontogenic carcinoma occurring in a dentigerous cyst: A case report and clinical management. J Periodontol 2000;71:1365-70.

14. Yasuoka T, Yonemoto K, Kato Y, Tatematsu N. Squamous cell carcinoma arising in a dentigerous cyst. J Oral Maxillofac Surg 2000;58:900-5.

15. Wine WM, Welch JT, Graves RW. Marsupialization of a dentigerous cyst of the mandible: Report of case. J Oral Surg 1971;29:742-5.

16. Leung PC, Chow SK, Ma GF. Primary reconstruction of the mandible after excision of large benign lesions. Br J Plast Surg 1988;41:251-4.

17. Yih WY, Morita V. A modified technique for obliteration of large bony defects after cystectomy. J Oral Maxillofac Surg 1991;49:689-92. 